\title{
The role of natural killer cells in the early period of infection in murine cutaneous leishmaniasis
}

\author{
M.D. Laurenti ${ }^{1}$, \\ M. Gidlund ${ }^{2,5}$, \\ D.M. Ura', \\ I.L. Sinhorini ${ }^{4}$, \\ C.E.P. Corbett ${ }^{1}$ \\ and $\mathrm{H}$. Goto ${ }^{3}$
}

\author{
${ }^{1}$ Laboratório de Patologia de Moléstias Infecciosas, Departamento de Patologia, \\ Departamentos de ${ }^{2}$ Patologia and ${ }^{3}$ M edicina Preventiva, Instituto de Medicina Tropical \\ de São Paulo (LIM/38), Faculdade de M edicina, and ${ }^{4}$ Departamento de Patologia, \\ Faculdade de Medicina Veterinária e Zootecnia, Universidade de São Paulo, \\ São Paulo, SP, Brasil \\ ${ }^{5}$ Karolinska Institute, Stockholm, Sweden
}

\section{Correspondence \\ H. Goto \\ Instituto de Medicina Tropical \\ de São Paulo \\ Av. Dr. Enéas C. Aguiar, 470 \\ 05403-000 São Paulo, SP \\ Brasil \\ Fax: + 55-11-852-3622 \\ E-mail: hgoto@usp.br}

Presented at the XIII Annual M eeting of the Federação de Sociedades de Biologia Experimental, Caxambu, MG, Brasil, August 26-29, 1998.

Research supported by CAPES (No. 0025/95-20), FAPESP (No. 96/11004-0), and LIM/50 (HC-FMUSP).

$\ldots \ldots \ldots \ldots \ldots \ldots$

Received April 14, 1998

Accepted December 1, 1998

\begin{abstract}
In order to study the role of natural killer (NK) cells during the early period of Leishmania infection, BALB/c mice were selectively and permanently depleted of NK cells by injection with ${ }^{90} \mathrm{Sr}$ and subsequently infected with Leishmania (Leishmania) amazonensis (HSJD1 strain). ${ }^{90} \mathrm{Sr}$ is known to selectively deplete NK cells, leaving an intact T- and B-cell compartment and preserving the ability to produce both interferon alpha and IL-2. This method of depletion has advantages when compared with depletion using anti-NK cell monoclonal antibodies because the effect is permanent and neither activates complement nor provokes massive cell death. In the present study, after one month of treatment with ${ }^{90} \mathrm{Sr}$, the depletion of NK cells was shown by a more than ten-fold reduction in the cytotoxic activity of these cells: $2 \times 10^{6}$ spleen cells from NK-depleted animals were required to reach the same specific lysis of target cells effected by 0.15 $\mathrm{x} 10^{6}$ spleen cells from normal control animals. The histopathology of the skin lesion at 7 days after Leishmania infection showed more parasites in the NK cell-depleted group. This observation further strengthens a direct role of NK cells during the early period of Leishmania infection.
\end{abstract}

Both innate and specific elements of the immune system contribute to the control or the progression of leishmaniasis. At the beginning of the infection, innate elements have been shown to have an important role in influencing the outcome of the disease. Among them, complement has been shown to contribute to the evasion of the parasite and for visceral dissemination in hamsters infected with Leishmania (Leishmania) chagasi (1). It has also been shown that nonimmune natural killer (NK) cells are im-

\section{Key words}

- Cutaneous leishmaniasis

- NK cells

- Strontium 90

- Leishmania (Leishmania)

amazonensis portant in Leishmania infection as a source of IFN $\gamma$ with the potential to trigger the Th-1 type of immune response in cutaneous leishmaniasis $(2,3)$. In addition, using the mutant beige mice with low NK activity, the direct importance of NK cells in the development of visceral leishmaniasis has been shown (4). Recently, in mice with an intermittent suppression or depletion of NK cells by antiasialo GM1 or anti-NK1.1 monoclonal antibodies resulted in an increased susceptibility of mice to Leishmania major (5). 
Figure 1 - In vitro spleen cell NK activity from nomal (striped column) or NK-depleted (open column) mice. Spleen cells from control or ${ }^{90} \mathrm{Sr}$-treated mice $(0.6 \mu \mathrm{Ci} / \mathrm{g}$ body weight intraperitoneal injection) were tested in a $4 \mathrm{H}\left[{ }^{51} \mathrm{Cr}\right]$ release microcytotoxicity assay at the indicated effector to target ratio using YAC-1 as described in Ref. 6. Specific lysis $=($ (release (cpm) with effector cells - release in medium alone)/(release in distilled water - release in medium alone)) $\times 100$. Data are from two separate experiments yielding similar results. Data represent the mean of 5 animals in each group and the SD was less than $5 \%$ of the mean.

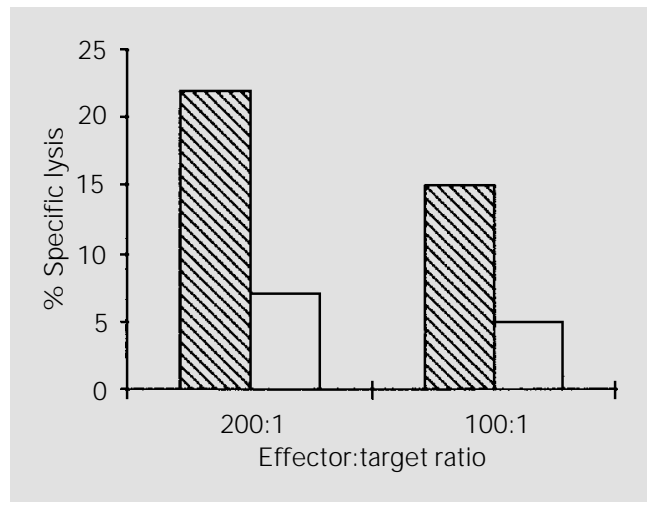

In the present study we have used ${ }^{90} \mathrm{Sr}$ to deplete NK cells. This treatment is well established and provides an intense local irradiation of the bone marrow leading to severe bone marrow aplasia with concomitant extramedullar myelopoiesis in the spleen $(6,7)$. The treatment has been shown to lead to a severe and permanent depletion of NK cell activity in the spleen, in the lymph nodes and in the periphery without any noticeable alteration in the T- or B-cell compartment or in the capacity to rapidly produce IL-2 or interferon alpha upon stimulation (6). Here we studied the effect of NK cell depletion by ${ }^{90} \mathrm{Sr}$ on the course of Leishmania (Leishmania) amazonensis infection.

Ten newly weaned BALB/c mice were depleted of NK cells by intraperitoneal injection of ${ }^{90} \mathrm{Sr}(0.6 \mu \mathrm{Ci} / \mathrm{g}$ body weight $)$ as previously described (6). After 30 days (i.e., after elimination of free ${ }^{90} \mathrm{Sr}$ ) they were infected subcutaneously in the hind footpad with $5 \times 10^{7}$ stationary phase promastigotes of Leishmania (L.) amazonensis (HSJD-1 strain) characterized by Prof. J.J. Shaw (Instituto Evandro Chagas, Brazil) according to the reactivity to monoclonal antibodies specific for $L$. (L.) amazonensis, $L$. (V.) panamensis and for the subgenus Viannia, and also by Dr. S.R. Uliana (Department of Parasitology, ICB, University of São Paulo, Brazil) according to the reactivity to subunit ribosomal DNA probes for $L$. amazonensis and the subgenus Viannia (8). Samples were taken to evaluate NK activity of spleen cells at the time of inoculation by a ${ }^{51} \mathrm{Cr}$ release cytotoxic assay of YAC-1 target cells. The level of parasite growth was verified by histopathological analysis of the skin lesion at seven days of infection.

The severe depletion of NK activity was confirmed by the lytic activity against YAC1 cells in ${ }^{90} \mathrm{Sr}$-treated animals (Figure 1). The calculated number of cells required in control animals to obtain the same level of lysis of target cells as found in NK-depleted animals (i.e., 7\% specific lysis) was shown to be $0.15 \times 10^{6}$ cells versus $2 \times 10^{6}$ spleen cells in NK-depleted animals. This demonstrated that the NK cell activity of ${ }^{90} \mathrm{Sr}-$


Figure 2 - Histopathology of skin lesions from control or NK-depleted mice infected with Leishmania (L.) amazonensis. Hematoxylin and eosin. Magnification, 40X. A, Mixed inflammatory infiltrate with few parasites is shown in control BALB/C mice. B, Mixed inflammatory infiltrate with more parasites is shown in NK-depleted BALB/C mice. 
treated mice was reduced more than ten times. As shown in Figure 2A and B, seven days after infection more parasites were observed in the skin lesion in ${ }^{90} \mathrm{Sr}$-treated mice. The inflammatory infiltrate characterized mainly by mononuclear cells with few polymorphonuclear neutrophils was similar in both groups.

Previous studies have similarly indicated a role for NK cells in leishmaniasis; however, our study clarified several important points. Several color mutants, including the beige mutant, have been shown to have reduced NK cells compared with their wild type counterpart (9). These mice also have severe alterations in the lysosomal compartment which affect macrophage and neutrophil functions. Therefore, there is uncertainty about the data obtained in beige mice and how the defects in phagocytes could interfere with the susceptibility of these mutant mice to Leishmania infection. The use of anti-asialo GM1 or NK1.1 antibodies leads to an intermittent and short-lived depletion of NK cells $(5,10)$ and furthermore, as is the case for any antibody used to deplete cell components in vivo, to a rapid activation of the complement that is known to be important in the initial phase of infection (1). Finally, it is highly likely that the rapid elimination of a sizable portion of the lymphocyte pool by the antibody can cause secondary effects due to complement activity and massive cell death. The ${ }^{90} \mathrm{Sr}$-treated mice have an advantage since they do not present any apparent change in monocyte function, as shown by the ability to mount a normal $\mathrm{T}$ and macrophage-dependent response to Con A detected by IL-2 production (6).

In a system with a selective depletion of NK cells along with an intact T- and B-cell compartment and with preserved ability to produce both interferon alpha and IL-2, we have shown increased Leishmania growth in the skin lesion. We conclude that the present data further support a direct role of NK cells in the early period of Leishmania infection.

\section{Acknowledgments}

We thank the Instituto de Pesquisas Energéticas da Universidade de São Paulo and Patrick Spencer for technical support during ${ }^{90} \mathrm{Sr}$ treatment.

\section{References}

1. Laurenti MD, Corbett CEP, Sotto MN, Sinhorini IL \& Goto H (1996). The role of complement in the acute inflammatory process in the skin and in host-parasite interaction in hamsters inoculated with Leishmania (Leishmania) chagasi. International J ournal of Experimental Pathology, 77: 15-24.

2. Scharton TM \& Scott P (1993). Natural killer cells are a source of interferon $\gamma$ that drives differentiation of $\mathrm{CD} 4+\mathrm{T}$ cell subsets and induces early resistance to Leishmania major in mice. J ournal of Experimental Medicine, 178: 567-577.

3. Scott $P$ (1991). IFN- $\gamma$ modulates the early development of Th1 and Th2 responses in a murine model of cutaneous leishmaniasis. J ournal of Immunology, 147: 31493155.

4. Kirkpatrick CE, Farrell JP, Warner JF \&
Dennert G (1985). Participation of natural killer cells in the recovery of mice from visceral leishmaniasis. Cellular Immunology, 92: 163-171.

5. Laskay $T$, Rollinghoff $M \&$ Solbach $W$ (1993). Natural killer cells participate in the early defense against Leishmania major infection in mice. European J ournal of Immunology, 23: 2237-2241.

6. Gidlund M, Bierke P, Öm A, Axberg I, Ramstedt U \& Wigzell H (1990). Impact of ${ }^{90} \mathrm{Sr}$ on mouse natural killer cells and their regulation by alpha-interferon and interleukin-2. Scandinavian J oumal of Immunology, 31: 575-582.

7. Haller O \& Wigzell H (1977). Suppression of natural killer cell activity with radioactive strontium: effector cells are marrow dependent. J ournal of Immunology, 118: 1503-1506.
8. Uliana SR, Nelson K, Beverly SM, Camargo EP \& Floeter-Winter LM (1994). Discrimination amongst Leishmania by polymerase chain reaction and hybridization with small subunit ribosomal DNA derived oligonucleotides. J ournal of Eukaryotic Microbiology, 41: 324-330.

9. Örn A, Gidlund M, Ramstedt U, Axberg I \& Wigzell H (1982). Four different pigment mutations in the mouse which also affect lysosomal function and all lead to suppressed NK cell activity. Scandinavian J ournal of Immunology, 15: 305-310.

10. Stein-Streilein J \& Guffee J (1986). In vivo treatment of mice and hamsters with antibodies to asialo GM 1 increases morbidity and mortality to pulmonary influenza infection. J ournal of Immunology, 136: 1435-1441. 